\title{
Effectiveness of yearly, register based screening for chlamydia in the Netherlands: controlled trial with randomised stepped wedge implementation
}

\author{
(c) $\underset{0}{(1)(8)}$ OPEN ACCESS
}

Ingrid V F van den Broek epidemiologist ${ }^{1}$, Jan E A M van Bergen professor of STI in primary care, general practitioner and programme manager ${ }^{23}$, Elfi E H G Brouwers public health/STI project officer ${ }^{4}$, Johannes S A Fennema director ${ }^{5}$, Hannelore M Götz consultant communicable disease control at centre for sexual health ${ }^{6}$, Christian J P A Hoebe head of department of infectious diseases control $^{4}$, Rik H Koekenbier researcher in department of infectious diseases control ${ }^{5}$, Mirjam Kretzschmar head of research group surveillance of infectious diseases ${ }^{17}$, Eelco A B Over health economist ${ }^{8}$, Boris V Schmid mathematical modeller ${ }^{1}$, Lydia L Pars public health researcher ${ }^{3}$, Sander $M$ van Ravesteijn public health/STI project officer ${ }^{9}$, Marianne A B van der Sande head of the department ${ }^{17}$, G Ardine de Wit health economist ${ }^{78}$, Nicola Low professor of epidemiology and public health medicine ${ }^{10}$, Eline L M Op de Coul epidemiologist ${ }^{1}$

\footnotetext{
${ }^{1}$ Unit of Epidemiology and Surveillance, RIVM/Centre for Infectious Disease Control Netherlands, PO Box 1, 3720 BA Bilthoven, Netherlands; ${ }^{2}$ University of Amsterdam, 1012 WX Amsterdam, Netherlands; ${ }^{3}$ STI AIDS Netherlands, Keizersgracht 390, 1016 GB Amsterdam, Netherlands; ${ }^{4}$ South Limburg Public Health Service, PO Box 2022, 6160 HA Geleen, Netherlands; ${ }^{5}$ Amsterdam Public Health Service, Nieuwe Achtergracht 100 , 1018 WT Amsterdam, Netherlands; ${ }^{6}$ Department of Infectious Disease Control, Municipal Public Health Service Rotterdam-Rijnmond, Po Box 70032 , 3000 LP Rotterdam, Netherlands; 7 Julius Centre for Health Sciences \& Primary Care, University Medical Centre Utrecht, Heidelberglaan 100, 3584 CX Utrecht, Netherlands; ${ }^{8}$ Centre for Prevention and Health Services Research, RIVM Netherlands. Bilthoven, Netherlands; ${ }^{9}$ Municipal Public Health Service Rotterdam-Rijnmond, Schiedamsedijk 95, 3011 EN Rotterdam, Netherlands; ${ }^{10}$ Institute of Social and Preventive Medicine, University of Bern, Finkenhubelweg 11, 3012 Bern, Switzerland
}

\author{
Abstract \\ Objective To evaluate the effectiveness of register based, yearly \\ chlamydia screening. \\ Design Controlled trial with randomised stepped wedge implementation \\ in three blocks. \\ Setting Three regions of the Netherlands: Amsterdam, Rotterdam, and \\ South Limburg. \\ Participants 317304 women and men aged 16-29 years listed on \\ municipal registers at start of trial. \\ Intervention From March 2008 to February 2011, the Chlamydia \\ Screening Implementation programme offered yearly chlamydia screening \\ tests. Postal invitations asked people to use an internet site to request \\ a kit for self collection of samples, which would then be sent to regional \\ laboratories for testing. Treatment and partner notification were done \\ by the general practitioner or at a sexually transmitted infection clinic.
}

\begin{abstract}
Main outcome measures Primary outcomes were the percentage of chlamydia tests positive (positivity), percentage of invitees returning a specimen (uptake), and estimated chlamydia prevalence. Secondary outcomes were positivity according to sex, age, region, and sociodemographic factors; adherence to screening invitations; and incidence of self reported pelvic inflammatory disease.

Results The participation rate was $16.1 \%$ (43 358/269 273) after the first invitation, $10.8 \%$ after the second, and $9.5 \%$ after the third, compared with $13.0 \%(6223 / 48031)$ in the control block invited at the end of round two of the intervention. Chlamydia positivity in the intervention blocks at the first invitation was the same as in the control block (4.3\%) and $0.2 \%$ lower at the third invitation (odds ratio 0.96 (95\% confidence interval 0.83 to 1.10)). No substantial decreases in positivity were seen after three screening rounds in any region or sociodemographic group. Among the people who participated three times (2.8\% of all invitees), positivity fell from $5.9 \%$ to $2.9 \%$ (odds ratio 0.49 ( 0.47 to 0.50$)$ ).
\end{abstract}


Conclusions There was no statistical evidence of an impact on chlamydia positivity rates or estimated population prevalence from the Chlamydia Screening Implementation programme after three years at the participation levels obtained. The current evidence does not support a national roll out of this register based chlamydia screening programme.

Trial registration NTR 3071 (Netherlands Trial Register, www. trialregister.nl).

\section{Introduction}

Chlamydia screening has been promoted as a means of controlling sexual transmission of Chlamydia trachomatis (chlamydia), ${ }^{1-3}$ which is the most common notifiable infection in some high income countries. ${ }^{1}$ Before introducing a screening programme there should be evidence from high quality randomised controlled trials that the screening programme is effective in reducing mortality or morbidity. ${ }^{4}$ The goals of chlamydia screening are to detect and treat asymptomatic infections, to limit ongoing transmission in the community, and to reduce the incidence of pelvic inflammatory disease. ${ }^{5}$ Pelvic inflammatory disease results from microorganisms, including $C$ trachomatis, ascending to the upper genital tract and is a strong risk factor for tubal factor infertility and ectopic pregnancy. ${ }^{6}$ The efficacy of a one-off offer of screening in preventing pelvic inflammatory disease has been shown in three randomised trials (in the US, Denmark, and UK), all of which reported a reduction in incidence in the intervention group after one year of follow-up. ${ }^{7-9}$ The most recent trial, with methods with the lowest risk of bias, showed the smallest effect (risk ratio 0.65 (95\% confidence interval 0.34 to 1.22$))^{9}{ }^{9}$

We lack evidence from randomised controlled trials that either opportunistic or register based repeated chlamydia screening reduces the prevalence of chlamydia in the population. ${ }^{10}$ Nevertheless, opportunistic chlamydia screening is widely practised. ${ }^{11} 12$ The National Chlamydia Screening Programme in England recommends chlamydia screening for sexually active women and men under 25 years of age every year and after a

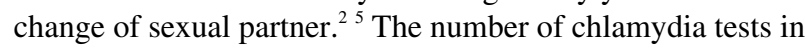
England has increased since the start of the programme in 2003 to cover $33 \%$ of all 15-24 year olds in 2010-11, when tests from both the programme and all other sources are included. ${ }^{13}$ The population impact of the programme is not known, however, because population chlamydia prevalence has never been measured as an end point. ${ }^{14}$ To evaluate the effect of screening on chlamydia transmission, multiple screening rounds and implementation of screening in geographically defined clusters are needed because repeated infection after treatment is common, ${ }^{15}$ and sexual partners need to be invited at the same time. ${ }^{16}$ This is because screening of a population in clusters is more likely to reduce immediate re-infection within sexual partnerships or transmission in local sexual networks than allocation of individuals to intervention and control groups and helps prevent "Why me?" questions that would arise if people in the same neighbourhoods received invitations at different times.

The feasibility of a single round of register based chlamydia screening has been examined in uncontrolled studies in the UK and the Netherlands. ${ }^{17-19}$ In the Netherlands, in 2002-03 kits for self sampling were sent to a selection of $2100015-29$ year old adults: $41 \%$ returned a sample, and $2.0 \%$ (95\% confidence interval $1.7 \%$ to $2.3 \%$ ) were chlamydia positive. ${ }^{19}$ On the basis of these results, the Dutch Ministry of Health decided to consider a national chlamydia screening programme if there was evidence of feasibility, effectiveness, and cost effectiveness. ${ }^{3}$ The objectives of this study were to investigate the effects of yearly invitations for chlamydia screening on the percentage of positive chlamydia test results (positivity), uptake of chlamydia screening, and estimated chlamydia prevalence among sexually active women and men in the Netherlands.

\section{Methods}

The intervention ${ }^{20}$ and evaluation ${ }^{21}$ of the Chlamydia Screening Implementation project have been described in detail. Results from the first year of screening, ${ }^{20-22}$ process evaluations, ${ }^{23}{ }^{24}$ and experiences of participants and non-responders ${ }^{25}$ have been published. The main features of the trial are summarised here.

\section{Study setting and participants}

The study took place in three regions of the Netherlands- the urban areas of Amsterdam and Rotterdam and a defined suburban area of South Limburg (Parkstad). All women and men aged 16-29 years old who were listed on the municipal population register from March 2008 to February 2011 were eligible to participate. Clusters were geographical and administrative units that included about 2000 people in the target age group in the cities and 1000 in South Limburg, resulting in 82 clusters (158 545 people) in Amsterdam, 62 clusters (119 868 people) in Rotterdam, and 46 clusters (38 891 people) in South Limburg.

\section{Interventions and blinding}

The intervention was a register based programme with personalised yearly invitations to be screened for $C$ trachomatis infection sent to the target population. The letter included the address of the programme website (www.chlamydiatest.nl) and a secure login code through which eligible participants could request a kit for self sampling (urine for men, vaginal swab or urine for women). ${ }^{20}$ Samples could be posted in prepaid secure packaging for testing by means of nucleic acid amplification tests. A single reminder letter was sent to anyone who did not access the website within four weeks, and email reminders were sent to individuals who requested a kit but did not return a specimen within two weeks. ${ }^{24}$ Test results, with a referral letter for those with positive results, were provided online, with an email or text message reminder after 14 and 28 days and a letter by post after six weeks for those who did not access it.

Treatment and partner notification were provided by the person's general practitioner or at a local sexually transmitted infections clinic. People with a positive test were sent a retest kit six months after treatment. In Amsterdam and Rotterdam, all people who reported that they ever had sex were asked to request a test kit. In South Limburg, chlamydia prevalence was expected to be lower than in the cities, and test kits were only sent to people completing a risk assessment form that had been developed previously. ${ }^{26} \mathrm{~A}$ risk score of $\geq 6$ with the form was compatible with a positivity of $4-5 \%$ and excluded $20-30 \%$ of potential participants. ${ }^{27}$ Participants provided informed consent online.

The control condition was usual care. Testing for chlamydia is available from general practitioners and at sexually transmitted infections clinics. There was no specific promotion of chlamydia testing during the trial period. Investigators, participants, and laboratory staff could not be blinded to allocation to intervention or control care.

\section{Comparison groups and randomised stepped wedge implementation}

The intervention was implemented by means of a stepped wedge design, with sequential roll out to clusters in a randomly determined order over time so that, by the end of the three year 
study period, each cluster had been invited at least once. ${ }^{21}$ The original study design encompassed 26 months of screening. To allow the evaluation of up to three screening rounds, clusters in the three regions were divided into three groups, called blocks $\mathrm{A}, \mathrm{B}$, and $\mathrm{C}$ (blocks were not geographically contiguous). Block A was smaller in the cities (one sixth of the population; invited three times); block B included two thirds of the population (invited twice); and block $\mathrm{C}$ (one sixth of the population, invited once after the second invitation was sent to blocks A and B) was the control group. The programme was subsequently prolonged by six months, allowing a third invitation in block B. In the smaller rural area, clusters were divided into three blocks of the same size to maximise statistical power.

Allocation of clusters - Clusters were allocated by two members of the evaluation team (ELMOdC and IVFvdB) who were blinded to the identity of clusters. Before allocation, clusters were stratified into three levels of community risk for chlamydia infection (high, medium, or low) based on demographic factors associated with chlamydia test positivity in the Netherlands (that is, proportions of 16-29 year olds, of Surinamese and Antillean residents, and of residents in the lowest income category; also level of urbanisation in the South Limburg region). ${ }^{19}$ For each region, cluster names were replaced by numbers and listed by cluster size and risk level. The investigators allocated de-identified clusters so that the required block sizes for A, B, and C were achieved and similar proportions of high, medium, and low risk target population per block were obtained. The results of the allocation and geographical distribution of clusters have been reported elsewhere. ${ }^{21}$

Randomised stepped wedge roll out-The order of invitation of clusters was randomised by assigning computer generated random numbers to clusters and then sorting clusters within one block using these numbers (using Microsoft Excel 2002). The order of clusters was then used to generate daily lists of 600 invitees from each of the regional municipal registers and forward these to the logistics company for mailing.

\section{Sample size calculation}

The sample size and numbers of clusters were determined by the actual size of the target population (16-29 year old women and men) in the three regions. The size of the control group blocks (one sixth of the population in the cities and one third in South Limburg) was determined to obtain maximum statistical power. Power calculations were based on the pilot feasibility study, which found participation of $30 \%$ and $3 \%$ of chlamydia tests positive in urban areas. ${ }^{19}$

Monte Carlo simulations of chlamydia positivity before and after screening in hypothetical clusters (assuming that positivity ranged from 0 to $10 \%$ with an average of $4 \%, 5 \%$, or $6 \%$ before screening) were run to determine the minimum detectable decline with given population numbers for the three regions and for each block. ${ }^{21}$ The trial had sufficient power $(80 \%, \alpha 0.05)$ to detect an absolute overall reduction of $1 \%$ in prevalence after one or two screening rounds if participation rates were at least $10 \%$ in Amsterdam and Rotterdam and 25\% in South Limburg with the baseline assumptions. After the first screening round, revised simulations resulted in a minimal detectable decline of $0.5 \%$ in positivity rate for Amsterdam, $0.8 \%$ in Rotterdam, and $1.2 \%$ in Limburg, whereas, for comparisons with the control block, the declines would need to exceed $1.2 \%$ to $1.5 \%$ if participation rates in the second and third rounds were similar.

\section{Outcomes}

The effectiveness of chlamydia screening was planned to be based on three primary outcomes; chlamydia test positivity, percentage participating, and estimated chlamydia prevalence in all regions. The main aim of the intervention was to reduce chlamydia prevalence in intervention areas, but prevalence could not be measured directly because, at the expected levels of screening uptake, the percentage of positive chlamydia tests is not a reliable estimate of population prevalence. The power calculation was therefore based on chlamydia positivity, and this is the primary outcome reported. Secondary outcomes were chlamydia test positivity and test uptake by sex, age, ethnic group, and region; estimated chlamydia prevalence; and incidence of self reported pelvic inflammatory disease.

\section{Statistical analysis}

We calculated absolute differences and odds ratios comparing chlamydia test positivity in intervention blocks and control blocks and, within intervention blocks, changes between the first and third rounds. Cluster effects for participation and positivity rates were calculated for round one using multivariable logistic regression with the variable "cluster" added as a second level. Clustering had a modest impact on participation rates (adjusted median odds ratio for cluster 1.14 (95\% confidence interval 1.11 to 1.16$), \mathrm{P}<0.001)$ and no impact on positivity (median odds ratio 1.03 (1.0 to 1.14)) so we report participation rates adjusted for clustering and positivity rates at the individual level. To account for baseline differences that might bias the estimate of impact on chlamydia positivity we included block allocation, community risk level, and cluster size as covariates and estimated the adjusted odds ratio.

The prevalence of chlamydia in the whole target population was estimated by extrapolation from positivity rates among participants by weighting based on demographic data available for all invitees and an estimate of people being sexually active. Therefore, cross tabulations of gender, age, ethnicity, and community risk in participants and invited populations were used to calculate survey weights for each invitation round (demographic data for the whole target population were obtained from the municipal register at the time of invitation). Weights were calculated by dividing the proportion of participants with a specified profile by the proportion of invitees with the same profile (for example, the profile " $<20$ year old, Dutch, male" represents $2 \%$ of the participant population but $4 \%$ of those invited, so the weight assigned is 2). Firstly, the crude prevalence in the invited population was estimated as the weighted positivity rate. Estimates were then further adjusted for sexual experience (assuming those who had never had sexual intercourse to be uninfected) by multiplying these crude prevalence rates by the fractions of sexually experienced women and men by one year age bands using data from the National Sexual Health Survey 2009. ${ }^{28}$ For South Limburg the estimates were also adjusted for the exclusion of people with lower levels of sexual risk behaviour by calculating a range of prevalence estimates with maximum values based on the assumption that the group excluded from participation because of a low score in the risk assessment had the same positivity rate as the lowest risk group included (with cut off score) and minimum values assuming this group had zero positivity.

Estimated chlamydia prevalence was a pre-specified outcome, but the results should be interpreted cautiously because probable differences between participants and non-participants in sexual risk level could not be taken into account (the information about sexual behaviour was not available for non-participants and for 
$55 \%$ of participants who did not fill in the online questionnaire at baseline). We considered multiple imputation of data but rejected it because the main parameters were systematically missing for all non-participants and not scattered throughout the dataset.

Secondary analyses compared changes in chlamydia positivity in each region and in demographic subgroups (age, gender, and ethnic group (based on participant's country of birth and that of his or her parents)). An indicator of socioeconomic status based on income, education level, and employment was available for the lowest level postcode areas (parts of streets) (Netherlands Institute for Social Research). An additional, voluntary set of questions about self reported pelvic inflammatory disease in the preceding year was offered to female participants after they had completed the general questionnaire (main question: "Have you been diagnosed with a pelvic infection (an infection in the ovaries or the uterus, not the bladder) in the past 12 months?"). We used SPSS version 18 (IBM Corporation, Somers, New York, USA) and SAS version 9.2 (SAS Institute, USA) for statistical analyses.

\section{Results \\ Population}

From March 2008 to February 2011 a total of 834971 invitations were sent to 421820 individuals aged 16-29 years in the three regions (table $1 \Downarrow$ ). Of these, 162096 received an invitation in each of three consecutive years, showing the mobility of the target population. Altogether, 102283 samples were returned by 79173 people, and 4252 cases of chlamydia infection were detected. At the time of analysis, 2661 of these cases were retested after six months (uptake $65 \%$ ). See the figure $\Downarrow$ for an overview of the study population in different stages of the trial.

\section{Participation}

After the first invitation, $16.1 \%$ (43 358/269 273) of invitees in blocks A and B returned a specimen; 10.8\% (28 803/265 979) returned one after the second invitation; and 9.5\% (23 899/251 688 ) after the third invitation. The participation rate in the control block $\mathrm{C}$ (invited after the second invitation in blocks $\mathrm{A}$ and B) was $13.0 \%$ (6223/48 031). Similar trends in participation rate per round were seen in each region (table $2 \Downarrow$ ). Participation in South Limburg was lower than in the cities because of the use of the risk assessment. The downward trend in participation over time was consistent across blocks when stratified by community risk level and cluster size.

Women were more likely to take part than men in all three invitation rounds (odds ratio, 2.34 (95\% confidence interval 2.31 to 2.38)). Participation rates were higher among older age groups (odds ratio 1.89 (1.85 to 1.92) for 25-29 year olds $v$ 16-19 year olds), Dutch invitees versus invitees of non-Dutch background (odds ratio 1.90 (1.87 to 1.92)), in people living in clusters of low community risk (odds ratio 1.57 (1.54 to 1.61) for low $v$ high risk areas), and for people living in postcode areas with high socioeconomic status scores (odds ratio 1.28 (1.24 to 1.33 ) for high $v$ low socioeconomic status). These differences were similar in consecutive screening rounds.

\section{Percentage of positive chlamydia test results (positivity)}

The overall chlamydia positivity rate was $4.3 \%$ (1851/43 358) among participants in the intervention blocks at the first invitation, $4.0 \%(1153 / 28803)$ at the second, and 4.1\% (981/23
899 ) at the third invitation (table $3 \Downarrow$ ). Chlamydia positivity in the intervention blocks at the first invitation was the same as in the control block $(4.3 \%$, table $1 \Downarrow)$ and $0.2 \%$ lower at the third invitation than in the control block (odds ratio 0.96 (0.83 to 1.10)). The positivity rates in the control blocks in each region were not all similar with those of the intervention blocks at the start (table $3 \Downarrow$ ). The difference between chlamydia positivity in the intervention blocks at the third invitation and in the control block was $0.05 \%$ in Amsterdam (3.4\% v 3.4\%, odds ratio 1.01 ( 0.81 to 1.26$)),-0.27 \%$ in Rotterdam $(5.3 \% v 5.5 \%$, odds ratio 0.95 (0.77 to1.16)), and $-1.02 \%$ in South Limburg (3.1\%v $4.1 \%$, odds ratio 0.74 ( 0.45 to 1.21$)$ ) (table $3 \Downarrow$ ). In South Limburg the difference reached the minimum level detectable in power calculations, but statistical evidence for a difference was weak because of low participation rates. There were some differences in changes in positivity between blocks A and B but these were not systematically related to community risk level or cluster size. The odds for chlamydia positivity in the first compared with the third invitation in all regions combined, controlling for block allocation, community risk level, and cluster size, was 0.97 (0.90 to 1.05$)$, similar to the unadjusted odds ratio.

Overall, women were more often chlamydia positive than men ( $4.2 \%$ v $3.8 \%$, odds ratio 1.12 (1.04 to 1.21$)$ ). Chlamydia positivity rates were higher in young people under 20 years old than among older invitees in all three rounds: at the first invitation, $7.1 \%$ in $<20$ year olds, $4.9 \%$ in $20-24$ year olds, and $2.7 \%$ in $25-29$ year olds (odds ratio 2.70 (2.47 to 2.95 )). There were no marked differences in the change in positivity after two or three invitations according to age. The positivity rate was generally higher in clusters categorised as being at high risk than low risk ( $6.7 \% v 3.0 \%$, odds ratio 2.30 (2.10 to 2.52$)$ ), in postcode areas with low socioeconomic status scores compared with areas with high scores ( $4.6 \% v 2.4 \%$, odds ratio 1.91 (1.54 to 2.37)) and among participants with non-Dutch background compared with a Dutch background (5.6\% v 3.4\%, odds ratio 1.63 (1.53 to 1.74$)$ ). Declines in positivity were slightly greater in high risk clusters than low risk clusters $(-0.3 \% v 0.0 \%)$, in low socioeconomic status postcodes than high status postcodes $(-0.8 \% v-0.1 \%)$, and in non-Dutch ethnic groups than Dutch groups $(-0.5 \% v-0.1 \%)$.

\section{Repeated participation}

People who had participated in a previous screening round were more likely to participate again: $28-30 \%$ of initial participants responded again when re-invited (round two $n=10474$, round three $n=8298$ ); $51 \%$ of people who participated twice did so again at the third invitation ( $\mathrm{n}=6001)$, but only $5 \%$ of those who had not participated earlier did so on a following invitation. Over three screening rounds, $25 \%$ of people who were invited three times participated at least once (39 854), 8.3\% participated twice (13 441/162 096), and 2.8\% participated three times (4510/162 096). Among the people who participated in all three rounds, the percentage with a positive chlamydia test fell from $5.9 \%$ in round one $(264 / 4510)$ to $2.9 \%(131 / 4510)$ in round three (difference $-3.0 \%$, odds ratio 0.49 (0.47 to 0.50$)$ ).

\section{Incidence of self reported pelvic inflammatory disease}

The question on pelvic inflammatory disease was answered by about $20 \%$ of female participants who completed the general questionnaire $(n=6420)$. Of these, $103(1.6 \%)$ answered "Yes" to having been diagnosed with a pelvic infection in the previous year, while 300 women (4.8\%) answered "I don't know for sure." Among these "unsure" respondents there were 20 cases 
of potential pelvic inflammatory disease, comprising ovarian infections diagnosed by ultrasound or other related medical procedures or reporting symptoms consistent with infection. The incidence of pelvic inflammatory disease among respondents, including these possible cases, would be $1.9 \%$. The self reported incidence did not change over the three invitations: $1.8 \%(19 / 1072)$ at the first invitation, $2.1 \%$ (47/2261) at the second, and 1.9\% (44/2340) at the third (odds ratio 1.06 (0.62 to 1.83 ) comparing first with third invite).

\section{Estimated population prevalence}

The estimated population prevalence was lower than positivity rates among the screening participants: $2.6 \%$ in Amsterdam, $3.7 \%$ in Rotterdam, and 3.2\% in South Limburg in round one (table $3 \Downarrow$ ). The estimated prevalence in the third invitation round was lower than in the control area in Amsterdam (2.5\% v 3.0\%) and South Limburg (1.8\% v 2.5\%), but not in Rotterdam (both $3.9 \%)$. Prevalence estimates were generally higher in men than in women; the decline in prevalence was strongest in women aged $>20$ years.

\section{Discussion}

\section{Main findings}

In this controlled trial the participation rate was lower than expected from an earlier pilot study and declined over the three screening rounds. The chlamydia positivity rate in the intervention blocks was $4.3 \%$ at baseline and $4.1 \%$ at the third invitation, compared with $4.3 \%$ in the control block. There was no statistical evidence of a reduction in chlamydia positivity in the whole target population from systematic population based screening, although results in South Limburg, where a risk based selection was added, were more promising than in Amsterdam and Rotterdam. Among the people taking part in all three years ( $2.8 \%$ of all participants), chlamydia positivity declined from $6 \%$ at the first test to $3 \%$ at the third (difference $-3.0 \%$, odds ratio $0.49(0.47$ to 0.50$))$.

\section{Strengths and weaknesses of study}

The main strengths of this trial were the evaluation of three yearly rounds of chlamydia screening invitations in different geographical settings in the Netherlands and the use of population registers that showed who had and had not taken part in screening. The stepped wedge design allowed comparisons between screened and non-screened areas in a logistically feasible way.

A limitation to the design of the trial was the non-random allocation of clusters to intervention and control blocks. This might have introduced selection bias if investigators deliberately allocated specific clusters to block A, which was planned to have the most screening rounds. We do not think this happened because the investigators were blinded to the identity of clusters and did not know whether the intervention effect might differ by risk level or cluster size. The subsequent randomisation of the order of implementation within blocks and addition of a third round of screening in block B would also reduce the risk of bias in the results.

The allocation achieved blocks of the required size, and the magnitude of baseline imbalances according to level of chlamydia risk could also have arisen by chance with random allocation, which is acknowledged as a limitation of group level interventions when the number of clusters is limited. ${ }^{29}$ Although we stratified the clusters according to community risk level, the intervention and control block were not completely comparable in all three regions. In addition, cluster allocation could have reduced, but not eliminated, transmission of chlamydia within clusters. Sexual networks do not strictly follow geographical boundaries and the blocks for implementation were not contiguous. Opportunities for chlamydia transmission between clusters receiving screening invitations at different times would dilute the effect of the intervention.

Of note, the participation rate in the control block $\mathrm{C}$ was not completely comparable to that achieved after the first invitation in the intervention blocks $\mathrm{A}$ and $\mathrm{B}$, but was in between the participation rates in rounds 1 and 2 . Invitees in the control group received their first invitation only in the second year of the programme. It is conceivable that the initial uptake was stimulated by the novelty and the boost of the publicity generated at the start of the screening, the effect of which would have waned by the time the control group got the invitation.

In practice, low uptake was probably the greatest barrier to interrupting transmission. The low uptake also made it impossible to estimate chlamydia prevalence reliably using multiple imputation methods. Because of the lower than expected participation, the estimates were extrapolated from a small proportion of the target population. In addition, the weights were based on demographics and proportion of people who are sexually experienced but not other behavioural data. The inverse probability weighting method assumed that prevalence in the unscreened population was the same as in participants with the same demographic profile. This is unlikely because people accepting an offer to be screened for chlamydia had higher levels of sexual risk behaviour and risk of chlamydia infection than the general population, especially at the second and third invitation. ${ }^{22}{ }^{28} 30$ Therefore, we expect that the true prevalence will be lower and the decline steeper.

\section{Comparison with other studies}

The results of this randomised trial give new information about the effects of register based chlamydia screening over multiple screening rounds on chlamydia prevalence at modest levels of uptake. To our knowledge, these are the least biased estimates available to date. Previous evidence came from ecological time trend studies showing declines in rates of diagnosed chlamydia or chlamydia positivity from countries conducting opportunistic chlamydia screening from the late 1980 s to mid 1990 s. $^{31-33}$ It is difficult to know how much of the declines in these studies were attributable to screening efforts because this time period coincided with the early phase of the HIV epidemic, when there were major publicity campaigns to encourage safer sexual practices and reductions in sexual risk behaviour. ${ }^{11}$

Participation rates in this trial decreased after each round, which was unexpected. However, this pattern has also been observed for bowel cancer screening in the UK. ${ }^{34}$ The uptake of opportunistic chlamydia screening in England has increased over time with coverage of $33 \%$ in $2010-11 .{ }^{14}$ The studies that examined the feasibility of one-off chlamydia screening invitations showed higher uptake rates. The Dutch Ct-Pilot Screening project achieved $30 \%$ participation in highly urbanised areas. ${ }^{19}$ The Chlamydia Screening Studies (ClaSS) project in England resulted in a 35\% participation rate. ${ }^{17}{ }^{18}$ In those studies, the kits for home collection of specimens were sent to the invitees (which is very costly to sustain), whereas in our trial people had to log in to an internet website to request the kit. In the United States, an internet based project offering chlamydia screening has reported increasing numbers of participants over time but does not actively offer regular 
screening, and numbers of test requests are low when related to population size. ${ }^{35-37}$

\section{Interpretation}

The aim of the Chlamydia Screening Implementation programme using home collected specimens was to supplement the coverage of existing, clinic based, opportunistic chlamydia testing to reduce the prevalence of chlamydia infection. However, in spite of a personal invitation letter, easy online home based procedures, and the use of text messaging and email reminders to increase response rates, participation was too low to reduce chlamydia transmission in the target population over the three years of the intervention. The impact on self reported pelvic inflammatory disease could not be assessed reliably. It is still possible that register based chlamydia screening could reduce chlamydia prevalence at the population level given more time or in a different population, but we have observed that the coverage and frequency of regular testing needed to achieve this goal were not easy to reach.

There are several possible reasons for the lack of observed effectiveness of chlamydia screening in this trial. First, the intervention might not have been intensive enough to achieve an effect. Second, any effect in the intervention blocks might have been diluted by contamination from unscreened clusters or areas outside the intervention regions. Third, the effective difference in screening coverage between intervention and control blocks was reduced by ongoing opportunistic testing activity.

There are two lines of evidence suggesting that the intensity of the intervention played a role. First, the percentage of positive chlamydia tests fell markedly among people who were screened in all three rounds. This effect was limited to only $3 \%$ of all eligible participants, however. The low uptake of yearly screening was in line with reports from Sweden, where, in a 10 year period, only $1.1 \%$ of women had 10 tests or more, ${ }^{38}$ and the US, which found that in a five year period $0.1 \%$ of women aged 15-25 years had a test every year. ${ }^{39}$ Second, in South Limburg the positivity and prevalence estimates declined more than in the cities. Here, a risk selection tool made screening more efficient, ${ }^{27}$ but it did not reach more people and the findings in this rural area cannot be extrapolated to urban populations directly.

People in both intervention and control blocks had access to chlamydia testing; the average self reported testing rate for the trial age group (16-29 years) in the Netherlands is estimated to be $10-12 \%$ per year. ${ }^{28}$ The level of regular screening by people tested opportunistically is not known. In the intervention blocks the response rate, restricting the denominator to the sexually active population, was $20 \%$ in the first year $(25 \%$ in women and $13 \%$ in men). ${ }^{22}{ }^{40}$ Overall chlamydia test coverage in the first year was therefore about $30 \%$ of sexually active $16-29$ year olds in the intervention blocks and $10 \%$ in the control block. It is not known whether home based sampling replaced testing in existing sexual health services, but visitor numbers at local sexually transmitted infection clinics did not fall during the study period. ${ }^{41}$ The positivity rates for chlamydia in sexually transmitted infections clinics (12-13\% for 16-29 year olds $)^{41}$ and general practice $\left(16 \%\right.$ positive of tested ${ }^{42}$ ) are higher than among those invited for screening, and people tested in sexually transmitted infection clinics report higher numbers of partners in the previous six months, more symptoms of infection, and lower levels of condom use. ${ }^{41}$ The behavioural risk profile of the participants in the Chlamydia Screening Implementation programme was higher than that of adults of the same age in the general population. ${ }^{22}$ On the other hand, non-responders seemed to be at lower risk of infection and chose not to participate for reasons such as not yet being sexually active, self perceived low risk, or having had a recent test. ${ }^{22}$ Participants who tested more than once tended to have higher risk sexual behaviour. ${ }^{27}{ }^{43}$ Self selection should have increased the yield of prevalent infections detected.

\section{Implications for research, practice and policy}

The results of this study provide unique data that can be used for future research. ${ }^{44}{ }^{45}$ A dynamic network simulation model, adapted from a previous model ${ }^{45}$ and using data from the programme, suggests a proportional decrease of $20-30 \%$ in positivity rates for chlamydia after 10 years if register based screening was added to current opportunistic testing. ${ }^{46}$ Cost effectiveness analysis indicates that this effect would be too small to reach acceptable incremental cost effectiveness ratios based on either major outcomes averted or quality adjusted life years gained. ${ }^{47}$ For clinical practice, the high levels of repeat infections after treatment $\left(9 \%\right.$ at six months $\left.{ }^{48}\right)$ suggest that improvements in case management and partner notification would benefit the infected individual.

The findings of the Chlamydia Screening Implementation programme provide valuable practice based evidence showing the limitations of the systematic screening approach in daily reality. This contradicts the suggestion from a modelling study that home based screening could have an impact on chlamydia prevalence within a few years, ${ }^{49}$ but supports an earlier UK expert opinion that register based chlamydia screening would not be effective. ${ }^{50}$ There is, however, still no evidence of effectiveness for the opportunistic approach chosen for the English National Chlamydia Screening Programme either. ${ }^{11}$ The results of the Australian Chlamydia Control and Effectiveness Pilot trial of multiple rounds of opportunistic chlamydia screening in general practice could fill this evidence gap by $2014 .^{51}$

There might be other settings where systematic screening would work, for example in countries with higher prevalence or lower levels of opportunistic testing. Evaluation of interventions in cluster randomised trials with biological end points would be valuable. The register based Chlamydia Screening Implementation programme showed that yearly individual invitations for three years and internet based home sampling were logistically feasible but did not achieve sufficient or sustained levels of uptake and did not reduce chlamydia prevalence when compared with the control population. The results of this trial do not support the national roll out of a register based chlamydia screening programme.

Contributors: All authors were involved in the conception, design, and implementation of the Chlamydia Screening Implementation and interpretation of the results. IVFvdB and ELMOdC developed the methods for the evaluation and analysed the data. JEAMvB and LLP were responsible for the coordination of the screening in the three regions; CJPAH and EEHGB for the screening in South Limburg, JSAF and RHK in Amsterdam, and HMG and SMvR in Rotterdam. BVS and MK designed the mathematical model, and EABO and GAdW developed the cost effectiveness model. MABvdS and NL contributed to the design of the evaluation of the programme. IVFvdB wrote the first draft of the manuscript. All authors provided feedback on drafts and read and approved the final manuscript. We acknowledge the contributions of $\mathrm{G}$ Doornbos and M Meijer for their support with statistical analysis and database management. We also thank the Chlamydia Screening Implementation Advisory Committee: T Bakkenist, $\mathrm{P}$ Bindels, $\mathrm{P}$ van den Broek, T Coenen, S de Gouw, B Hoebee, J Land, S Morré, R van Riel, 


\section{What is already known on this topic}

Chlamydia infection is the most common treatable sexually transmitted infection in many industrialised countries

Randomised controlled trials have examined the effect of chlamydia screening on the incidence of pelvic inflammatory disease but not on chlamydia prevalence

All published intervention studies have been limited to a single round of screening. Evidence of the impact of annual chlamydia screening has been limited to ecological and mathematical modelling studies

\section{What this study adds}

Three yearly rounds of register based chlamydia screening did not achieve a marked reduction in the percentage of people testing positive at each round

Participation rates were low and decreased with each successive round

The results of this trial do not support the national roll out of this register based chlamydia screening programme

$M$ van der Sande, and E Steyerberg for their advice and suggestions for improvement.

Funding: The Chlamydia Screening Implementation was carried out on request of the Ministry of Health, Welfare and Sport. The Dutch organisation for Health Research and Development (ZonMW, project number 12.400.001) funded the project.

Competing interests: All authors have completed the ICMJE uniform disclosure form at www.icmje.org/coi_disclosure.pdf (available on request from the corresponding author) and declare: no support from any organisation for the submitted work; no financial relationships with any organisations that might have an interest in the submitted work in the previous three years; no other relationships or activities that could appear to have influenced the submitted work.

Ethical approval: The Medical Ethics Committee Free University Amsterdam (Identification number 2007/239) approved the trial. Data sharing: Data sharing is possible; researchers should send a request and motivation for (parts of) the database or remaining sample material to the first or second author. A committee will then decide whether the data or samples can be used for the specific research purpose.

1 Centers for Disease Control and Prevention. Sexually transmitted diseases guidelines, 2010. MMWR 2010;59:1-114

2 Health Protection Agency. National chlamydia screening programme. Core requirements . 5th ed, update 2. Health Protection Agency, 2010.

3 Dutch Health Council. Screenen op Chlamydia. [Screening for Chlamydia.] Gezondheidsraad rapport. [Health Council Report.] Dutch Health Council, 2004.

4 UK National Screening Committee. UK screening portal. Programme appraisal criteria. 2011. www.screening.nhs.uk/cms. php?folder $=2431$.

5 National Chlamydia Screening Programme. The bigger picture. The national chlamydia screening programme 2008/09 annual report. 2011. www.chlamydiascreening.nhs.uk/ps/ publications/reports.html.

6 Weström L. Effect of pelvic inflammatory disease on fertility. Venereology 1995;8:219-22.

7 Scholes D, Stergachis A, Heidrich FE, Andrilla H, Holmes KK, Stamm WE. Prevention of pelvic inflammatory disease by screening for cervical chlamydial infection. $N$ Engl $J$ Med 1996;334:1362-6.

8 Østergaard L, Andersen B, Møller JK, Olesen F. Home sampling versus conventional swab sampling for screening of Chlamydia trachomatis in women: a cluster-randomized 1-year follow-up study. Clin Infect Dis 2000;31:951-7.

9 Oakeshott P, Kerry S, Aghaizu A, Atherton H, Hay S, Taylor-Robinson D, et al. Randomised controlled trial of screening for Chlamydia trachomatis to prevent pelvic inflammatory disease: the POPI (prevention of pelvic infection) trial. BMJ 2010;340:c1642.

10 Low N, Bender N, Nartey L, Shang A, Stephenson JM. Effectiveness of chlamydia screening: systematic review. Int J Epidemiol 2009:38:435-48.

11 Low N. Screening programmes for chlamydial infection: when will we ever learn? BMJ 2007;334:725-8

12 Low N, Cassell JA, Spencer B, Bender N, Martin Hilber A, van Bergen J, et al. Chlamydia control activities in Europe: cross-sectional survey. Eur J Public Health 2011: published online 29 April.

13 National Chlamydia Screening Programme. Chlamydia connects. The August 2011 eNewsletter from the NCSP. NCSP, 2011.

14 Woodhall SC, Mercer CH, Soldan K. Declining positivity among 15-24-year-olds screened for Chlamydia in England-a sign of falling prevalence or a symptom of changing uptake? Poster ISSTDR Conference, 10-13 July 2011, Quebec, Canada. Sex Transm Infect 2011;87:A113-4.

15 Batteiger BE, Xu F, Johnson RE, Rekart ML. Protective immunity to Chlamydia trachomatis genital infection: evidence from human studies. $J$ Infect Dis 2010;201(Suppl 2):S178-89.

16 Mercer CH, Copas AJ, Sonnenberg P, Johnson AM, McManus S, Erens B, et al. Who has sex with whom? Characteristics of heterosexual partnerships reported in a national probability survey and implications for STI risk. Int J Epidemiol 2009;38:206-14.

17 Macleod J, Salisbury C, Low N, McCarthy A, Sterne JAC, Holloway A, et al. Coverage and uptake of systematic postal screening for genital Chlamydia trachomatis and prevalence of infection in the United Kingdom general population: cross sectional study. BMJ 2005;330:940-2.
18 Low N, McCarthy A, Macleod J, Salisbury C, Campbell R, Roberts TE, et al, for the Chlamydia Screening Studies Project Group. Epidemiological, social, diagnostic and economic evaluation of population screening for genital chlamydial infection. Health Technol Assess 2007;11:1-186.

19 Van Bergen J, Götz HM, Richardus JH, Hoebe CJ, Broer J, Coenen AJ, et al. Prevalence of urogenital Chlamydia trachomatis increases significantly with level of urbanisation and suggests targeted screening approaches: results from the first national population based study in the Netherlands. Sex Transm Infect 2005;81:17-23.

20 Van Bergen JE, Fennema JS, van den Broek IV, Brouwers EE, de Feijter EM, Hoebe CJ, et al. Rationale, design, and results of the first screening round of a comprehensive, register-based, Chlamydia screening implementation programme in the Netherlands. BMC Infect Dis 2010;10:293.

21 Van den Broek IV, Hoebe CJ, van Bergen JE, Brouwers EE, de Feijter EM, Fennema JS, et al. Evaluation design of a systematic, selective, internet-based, Chlamydia screening implementation in the Netherlands, 2008-2010: implications of first results for the analysis. BMC Infect Dis 2010;10:89.

22 Op de Coul ELM, Götz HM, van Bergen JEAM, Fennema JSA, Hoebe CJPA, Koekenbier $\mathrm{RH}$, et al. Who participates in the Dutch Chlamydia screening? A study on demographic and behavioural correlates of participation and positivity. Sex Transm Dis 2012;39:97-103

23 Op de Coul ELM, Weenen TC, van der Sande MAB, van den Broek IVF. Process evaluation of the Chlamydia Screening Implementation in the Netherlands: phase 1. RIVM report 210261006. 2011. www.rivm.nl/bibliotheek/rapporten/210261006.html.

24 Dokkum NF, Koekenbier RH, van den Broek IV, van Bergen JE, Brouwers EE, Fennema JS, et al. Keeping participants on board: increasing uptake by automated respondent reminders in an Internet-based Chlamydia screening in the Netherlands. BMC Public Health 2012:12:176.

25 Greenland KE, Op de Coul EL, van Bergen JE, Brouwers EE, Fennema HJ, Götz HM, et al. Acceptability of the Internet-based Chlamydia screening implementation in the Netherlands and insights into nonresponse. Sex Transm Dis 2011;38:467-74.

26 Götz HM, van Bergen JE, Veldhuijzen IK, Broer J, Hoebe CJ, Steyerberg EW, et al. A prediction rule for selective screening of Chlamydia trachomatis infection. Sex Transm Infect 2005;81:24-30.

27 Van den Broek IV, Brouwers EE, Götz HM, van Bergen JE, Op de Coul EL, Fennema $\mathrm{JS}$, et al. Systematic selection of screening participants by risk score in a chlamydia screening programme is feasible and effective. Sex Transm Infect 2012;88:205-11.

28 Bakker $\mathrm{F}$, de Graaf $\mathrm{H}$, de Haas S, Kedde $\mathrm{H}$, Kruijer H, Wijsen C. Sexual health in the Netherlands. Rutgers Nisso Group Report, 2009.

29 Ukoumunne OC, Gulliford MC, Chinn S, Sterne JA, Burney PG, Donner A. Evaluation of health interventions at area and organisation level. BMJ 1999;319;376-9.

30 Riha J, Mercer CH, Soldan K, French CE, Macintosh M. Who is being tested by the English National Chlamydia Screening Programme? A comparison with national probability survey data. Sex Transm Infect 2011;87:306-11.

31 Herrmann BF, Johansson AB, Mårdh PA. A retrospective study of efforts to diagnose infections by Chlamydia trachomatis in a Swedish county. Sex Transm Dis 1991:18:233-7.

32 Addiss DG, Vaughn ML Ludka D, Pfister J, Davis JP. Decreased prevalence in Chlamydia trachomatis infection associated with a selective screening program of family planning clinics in Wisconsin. Sex Transm Dis 1993;20:28-35.

33 Hillis SD, Nakashima A, Amsterdam L, Pfister J, Vaughn M, Addiss D, et al. The impact of a comprehensive chlamydia prevention program in Wisconsin. Fam Plann Perspect 1995;27:108-11.

34 Szczepura A, Price C, Gumber A. Breast and bowel cancer screening uptake patterns over 15 years for UK south Asian ethnic minority populations, corrected for differences in socio-demographic characteristics. BMC Public Health 2008;8:346.

35 Gaydos CA, Dwyer K, Barnes M, Rizzo-Price PA, Wood BJ, Flemming T, et al. Internet-based screening for Chlamydia trachomatis to reach non-clinic populations with mailed self-administered vaginal swabs. Sex Transm Dis 2006;33:451-7. Erratum in: Sex Transm Dis 2007;34:625.

36 Gaydos CA, Barnes M, Aumakhan B, Quinn N, Agreda P, Whittle P, et al. Can e-technology through the Internet be used as a new tool to address the Chlamydia trachomatis epidemic by home sampling and vaginal swabs? Sex Transm Dis 2009;36:577-80.

37 Chai SJ, Aumakhan B, Barnes M, Jett-Goheen M, Quinn N, Agreda P, et al. Internet-based screening for sexually transmitted infections to reach nonclinic populations in the community: risk factors for infection in men. Sex Transm Dis 2010;37:756-63.

38 Low N, Egger M, Sterne JA, Harbord RM, Ibrahim F, Lindblom B, et al. Incidence of severe reproductive tract complications associated with diagnosed genital chlamydial infection: the Uppsala Women's Cohort Study. Sex Transm Infect 2006;82:212-8.

39 Heijne JC, Tao G, Kent CK, Low N. Uptake of regular chlamydia testing by US women: a longitudinal study. Am J Prev Med 2010;39:243-50.

40 Van den Broek IVF, Götz HM, Brouwers EEHG, Fennema JSA, Hoebe CJPA, Koekenbier $\mathrm{RH}$, et al. The contribution of a Chlamydia screening programme to testing and case-finding in addition to regular STI-care in three regions of The Netherlands. Poster ISSTDR Conference, 10-13 July 2011, Quebec, Canada. Sex Transm Infect 2011;87:A200-1.

41 Vriend HJ, Koedijk FDH, van den Broek IVF, van Veen MG, Op de Coul ELM, van Sighem $\mathrm{Al}$, et al. Sexually transmitted infections, including HIV, in the Netherlands in 2010. RIVM report 210261009. 2011. www.rivm.nl/Thema_s/Infectieziekten/Soa. 
42 Van den Broek I, Koedijk F, Donker G, van Bergen J, van der Sande M. Sexually transmitted infection consultations in general practice in the Netherlands. Poster at the $25^{\text {th }}$ IUSTI Europe Conference, September 2010, Tblisi, Georgia.

43 Op de Coul E, Götz H, van Bergen J, Brouwers E, Fennema H, Hoebe C, et al. Who participates in the Dutch chlamydia screening? A study on demographic and behavioural correlates of (repeated) participation and positivity. Poster ISSTDR Conference, 10-13 July 2011, Quebec, Canada. Sex Transm Infect 2011;87:A343.

44 Turner KM, Adams EJ, Lamontagne DS, Emmett L, Baster K, Edmunds WJ. Modelling the effectiveness of chlamydia screening in England. Sex Transm Infect 2006;82:496-502.

45 Kretzschmar M, Turner KM, Barton PM, Edmunds WJ, Low N. Predicting the population impact of chlamydia screening programmes: comparative mathematical modelling study. Sex Transm Infect 2009;85:359-66.

46 Schmid BV, van den Broek IVF, Op de Coul ELM, van Bergen JEAM, Fennema JSA, Götz HM, et al. Modelled impact of changing participation rates on effectiveness of population based Chlamydia screening. Oral presentation ISSTDR Conference, 10-13 July 2011, Quebec, Canada. Sex Transm Infect 2011;87:A45-6.

47 Schmid B, Over E, van den Broek I, Op de Coul E, van Bergen J, CSI Group, et al. Chlamydia screening implementation in the Netherlands is not cost-effective. Poster ISSTDR Conference, 10-13 July 2011, Quebec, Canada. Sex Transm Infect 2011:87:A344.

48 Götz HM, Op de Coul ELM, Brouwers EEHG, Fennema JSA, Hoebe CJPA, Koekenbie $\mathrm{RH}$, et al. Reinfections, treatment and partner notification in a selective systematic internet based Chlamydia screening programme. Oral presentation ISSTDR Conference, 10-13 July 2011, Quebec, Canada. Sex Transm Infect 2011;87:A21-2.
49 Andersen B, Gundgaard J, Kretzschmar M, Olsen J, Welte R, Oster-Gaard L. Prediction of costs, effectiveness, and disease control of a population-based program using home sampling for diagnosis of urogenital Chlamydia trachomatis infections. Sex Transm Dis 2006;33:407-15.

50 Anonymous. CMO's Expert advisory group on Chlamydia trachomatis. Department of Health, 1998.

51 Hocking JS, Temple-Smith M, Poznznski S, Guy R, Low N, Donovan B, et al, ACCEP Consortium. Australian chlamydia control effectiveness pilot: preliminary results from a trial of chlamydia testing in general practice. Poster ISSTDR Conference, 10-13 July 2011, trial of chlamydia testing in general practice. Poster ISSTL

Accepted: 15 May 2012

\section{Cite this as: BMJ 2012;345:e4316}

This is an open-access article distributed under the terms of the Creative Commons Attribution Non-commercial License, which permits use, distribution, and reproduction in any medium, provided the original work is properly cited, the use is non commercial and is otherwise in compliance with the license. See: http://creativecommons.org/licenses/by$\mathrm{nc} / 2.0 /$ and http://creativecommons.org/licenses/by-nc/2.0/legalcode. 


\section{Tables}

Table 1| Baseline characteristics of clusters and individuals in the Chlamydia Screening Implementation programme, by block at enrolment (see text for details)

\begin{tabular}{|c|c|c|c|c|c|c|c|c|c|c|c|c|}
\hline & \multicolumn{3}{|c|}{ Block A } & \multicolumn{3}{|c|}{ Block B } & \multicolumn{3}{|c|}{ Block C } & \multicolumn{3}{|c|}{ Total } \\
\hline & $\begin{array}{c}\text { No of } \\
\text { clusters } \\
(n=39)\end{array}$ & $\begin{array}{c}\text { No of } \\
\text { individuals } \\
(n=55776)\end{array}$ & $\begin{array}{c}\% \text { of } \\
\text { total } \\
\text { per } \\
\text { block }\end{array}$ & $\begin{array}{l}\text { No of } \\
\text { clusters } \\
(n=114)\end{array}$ & $\begin{array}{c}\text { No of } \\
\text { individuals } \\
(n=213 \quad 497)\end{array}$ & $\begin{array}{l}\% \text { of } \\
\text { total } \\
\text { per } \\
\text { block }\end{array}$ & $\begin{array}{c}\text { No of } \\
\text { clusters } \\
(n=37)\end{array}$ & $\begin{array}{c}\text { No of } \\
\text { individuals } \\
(n=48 \text { 031) }\end{array}$ & $\begin{array}{c}\% \text { of } \\
\text { total } \\
\text { per } \\
\text { block }\end{array}$ & $\begin{array}{l}\text { No of } \\
\text { clusters } \\
(n=190)\end{array}$ & $\begin{array}{c}\text { No of } \\
\text { individuals } \\
(n=317304)\end{array}$ & $\begin{array}{l}\% \text { of } \\
\text { total }\end{array}$ \\
\hline \multicolumn{13}{|l|}{ Community risk: } \\
\hline High & 7 & 10569 & 18.9 & 21 & 36732 & 17.2 & 6 & 11331 & 23.6 & 34 & 58632 & 18.5 \\
\hline Medium & 19 & 30401 & 54.5 & 54 & 113141 & 53.0 & 18 & 23625 & 49.2 & 91 & 167167 & 52.7 \\
\hline Low & 13 & 14806 & 26.5 & 39 & 63624 & 29.8 & 13 & 13075 & 27.2 & 65 & 91505 & 28.8 \\
\hline \multicolumn{13}{|l|}{ Cluster size (quarters): } \\
\hline 197-1596 & 26 & 23619 & 42.3 & 45 & 45078 & 21.1 & 25 & 20702 & 43.1 & 96 & 89399 & 28.2 \\
\hline 1597-2209 & 5 & 9080 & 16.3 & 29 & 55063 & 25.8 & 7 & 13324 & 27.7 & 41 & 77467 & 24.4 \\
\hline 2210-2825 & 5 & 12257 & 22.0 & 24 & 60219 & 28.2 & 2 & 4484 & 9.3 & 31 & 76960 & 24.3 \\
\hline $2826-4538$ & 3 & 10820 & 19.4 & 16 & 53137 & 24.9 & 3 & 9521 & 19.8 & 22 & 73478 & 23.2 \\
\hline \multicolumn{13}{|l|}{ Region: } \\
\hline Amsterdam & 13 & 25072 & 45.0 & 56 & 114847 & 53.8 & 13 & 18626 & 38.8 & 82 & 158545 & 50.0 \\
\hline Rotterdam & 10 & 17543 & 31.5 & 42 & 85792 & 40.2 & 10 & 16533 & 34.4 & 62 & 119868 & 37.8 \\
\hline South Limburg & 16 & 13161 & 23.6 & 16 & 12858 & 6.0 & 14 & 12872 & 26.8 & 46 & 38891 & 12.3 \\
\hline \multicolumn{13}{|l|}{ Gender: } \\
\hline Male & - & 26928 & 48.3 & - & 102534 & 48.0 & - & 23884 & 49.7 & - & 153346 & 48.3 \\
\hline Female & - & 28848 & 51.7 & - & 110963 & 52.0 & - & 24147 & 50.3 & - & 163958 & 51.7 \\
\hline \multicolumn{13}{|l|}{ Age (years): } \\
\hline $16-19$ & 一 & 12406 & 22.2 & 一 & 45667 & 21.4 & - & 9574 & 19.9 & - & 67647 & 21.3 \\
\hline $20-24$ & - & 20569 & 36.9 & - & 77599 & 36.3 & - & 18581 & 38.7 & - & 116749 & 36.8 \\
\hline $25-29$ & - & 22801 & 40.9 & - & 90231 & 42.3 & - & 19876 & 41.4 & - & 132908 & 41.9 \\
\hline \multicolumn{13}{|l|}{ Ethnic origint: } \\
\hline Dutch & - & 29670 & 53.2 & - & 105018 & 49.2 & - & 24692 & 51.4 & - & 159380 & 50.2 \\
\hline Surinamese/Antillean & - & 4210 & 7.5 & - & 24195 & 11.3 & - & 4315 & 9.0 & - & 32720 & 10.3 \\
\hline Turkish/Moroccan & - & 9293 & 16.7 & - & 33593 & 15.7 & - & 7801 & 16.2 & - & 50687 & 16.0 \\
\hline Sub-Saharan African & - & 1727 & 3.1 & - & 7804 & 3.7 & - & 1814 & 3.8 & - & 11345 & 3.6 \\
\hline Other & - & 10876 & 19.5 & - & 42887 & 20.1 & - & 9409 & 19.6 & - & 63172 & 19.9 \\
\hline \multicolumn{13}{|c|}{ Participation and chlamydia test positivity } \\
\hline Participation (\%) & & 15.5 & & & 16.3 & & & 13.0 & & & 15.6 & \\
\hline $\begin{array}{l}\text { Chlamydia positivity } \\
(\%)\end{array}$ & & 4.31 & & & 4.27 & & & 4.30 & & & 4.28 & \\
\hline
\end{tabular}




\begin{tabular}{|c|c|c|c|}
\hline & No of people invited & No of people participated & Participation rate $(\%(95 \% \mathrm{Cl}))^{*}$ \\
\hline Total: & 834971 & 102283 & $12.2(11.7$ to 12.8$)$ \\
\hline 1st invitation & 269273 & 43358 & $16.1(15.3$ to 16.9$)$ \\
\hline 2nd invitation & 265979 & 28803 & $10.8(10.3$ to 11.4$)$ \\
\hline 3rd invitation & 251688 & 23899 & $9.5(9.0$ to 10.0$)$ \\
\hline Control & 48031 & 6223 & $13.0(11.4$ to 14.7$)$ \\
\hline \multicolumn{4}{|l|}{ Region } \\
\hline \multicolumn{4}{|l|}{ Amsterdam: } \\
\hline 1st invitation & 139919 & 24059 & $17.2(16.4$ to 18.3$)$ \\
\hline 2nd invitation & 136689 & 16355 & $12.0(11.2$ to 12.8$)$ \\
\hline 3rd invitation & 133736 & 13866 & 10.4 (9.6 to 11.3$)$ \\
\hline Control & 18626 & 2899 & $15.6(12.5$ to 19.3$)$ \\
\hline \multicolumn{4}{|l|}{ Rotterdam: } \\
\hline 1st invitation & 103335 & 16414 & $15.8(14.6$ to 17.1$)$ \\
\hline 2nd invitation & 104692 & 10753 & $10.2(9.5$ to 11.0$)$ \\
\hline 3rd invitation & 104885 & 9057 & $8.7(8.0$ to 9.4$)$ \\
\hline Control & 16533 & 2254 & $13.6(11.8$ to 15.6$)$ \\
\hline \multicolumn{4}{|l|}{ South Limburg: } \\
\hline 1st invitation & 26019 & 2885 & 11.1 (10.1 to 12.3$)$ \\
\hline 2nd invitation & 24598 & 1687 & $6.9(6.2$ to 7.6$)$ \\
\hline 3rd invitation & 13067 & 874 & $6.7(5.8$ to 7.6$)$ \\
\hline Control & 12872 & 1070 & $8.3(7.1$ to 9.8$)$ \\
\hline \multicolumn{4}{|l|}{ Gender } \\
\hline \multicolumn{4}{|l|}{ Male: } \\
\hline 1st invitation & 129462 & 13617 & $10.5(10.0$ to 11.0$)$ \\
\hline 2nd invitation & 128299 & 8616 & $6.7(6.4$ to 7.0$)$ \\
\hline 3rd invitation & 121156 & 6970 & $5.8(5.5$ to 6.0$)$ \\
\hline Control & 23884 & 2025 & 8.5 (7.6 to 9.5$)$ \\
\hline \multicolumn{4}{|l|}{ Female: } \\
\hline 1st invitation & 142419 & 29831 & 21.3 (20.3 to 22.3$)$ \\
\hline 2nd invitation & 141078 & 20246 & $14.7(13.9$ to 15.4$)$ \\
\hline 3rd invitation & 131010 & 16853 & $13.0(12.2$ to 13.8$)$ \\
\hline Control & 24172 & 4199 & $17.4(15.1$ to 19.9$)$ \\
\hline
\end{tabular}

${ }^{*}$ Confidence intervals are corrected for cluster effect (inter-cluster effect on participation was significant). 


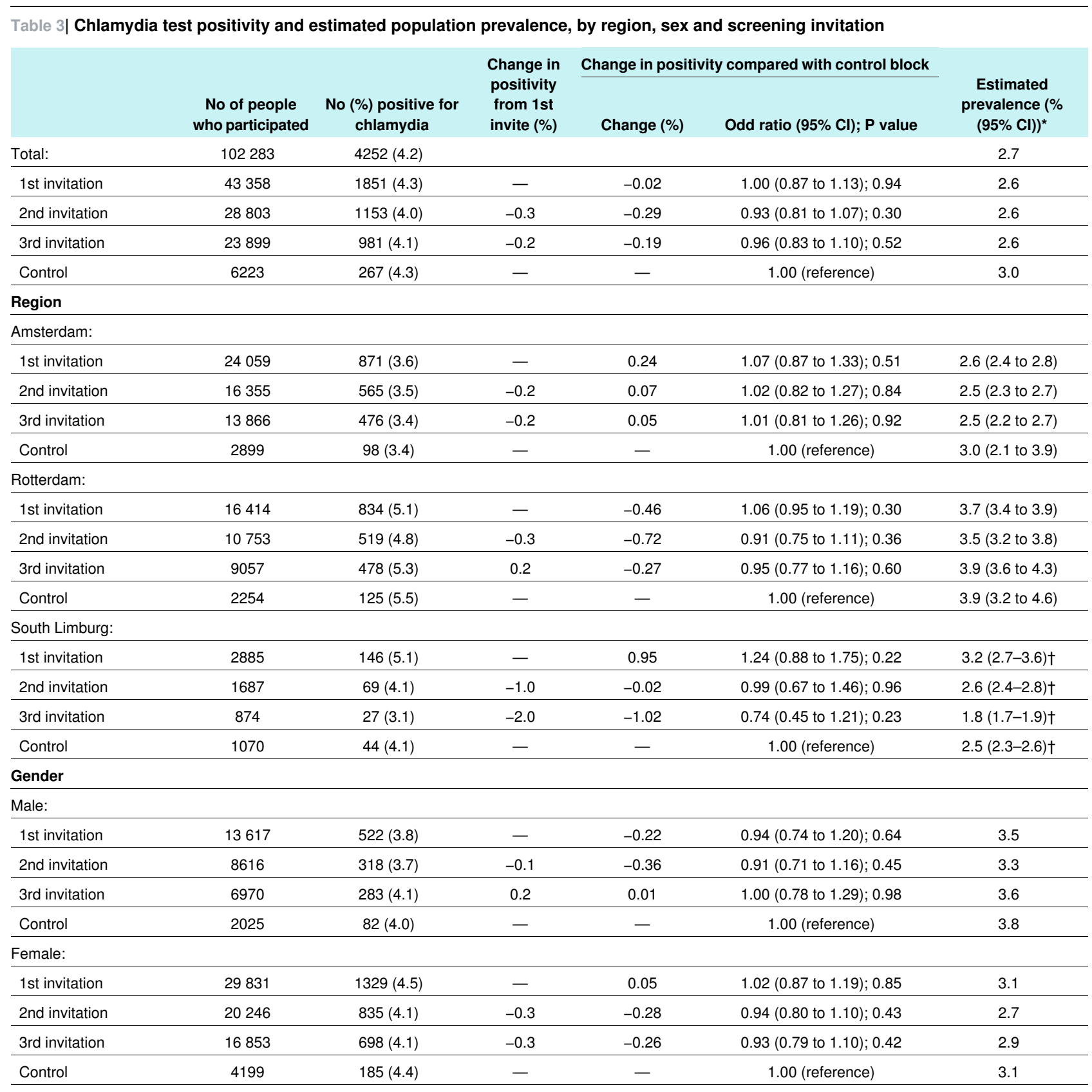

*Confidence intervals are not corrected for cluster effect (inter-cluster effect on positivity was not significant). Confidence intervals could not be calculated for South Limburg, so they are also unavailable for the total population and estimates by gender.

†Values are intermediates with high and low estimates rather than confidence intervals. 


\section{Figure}

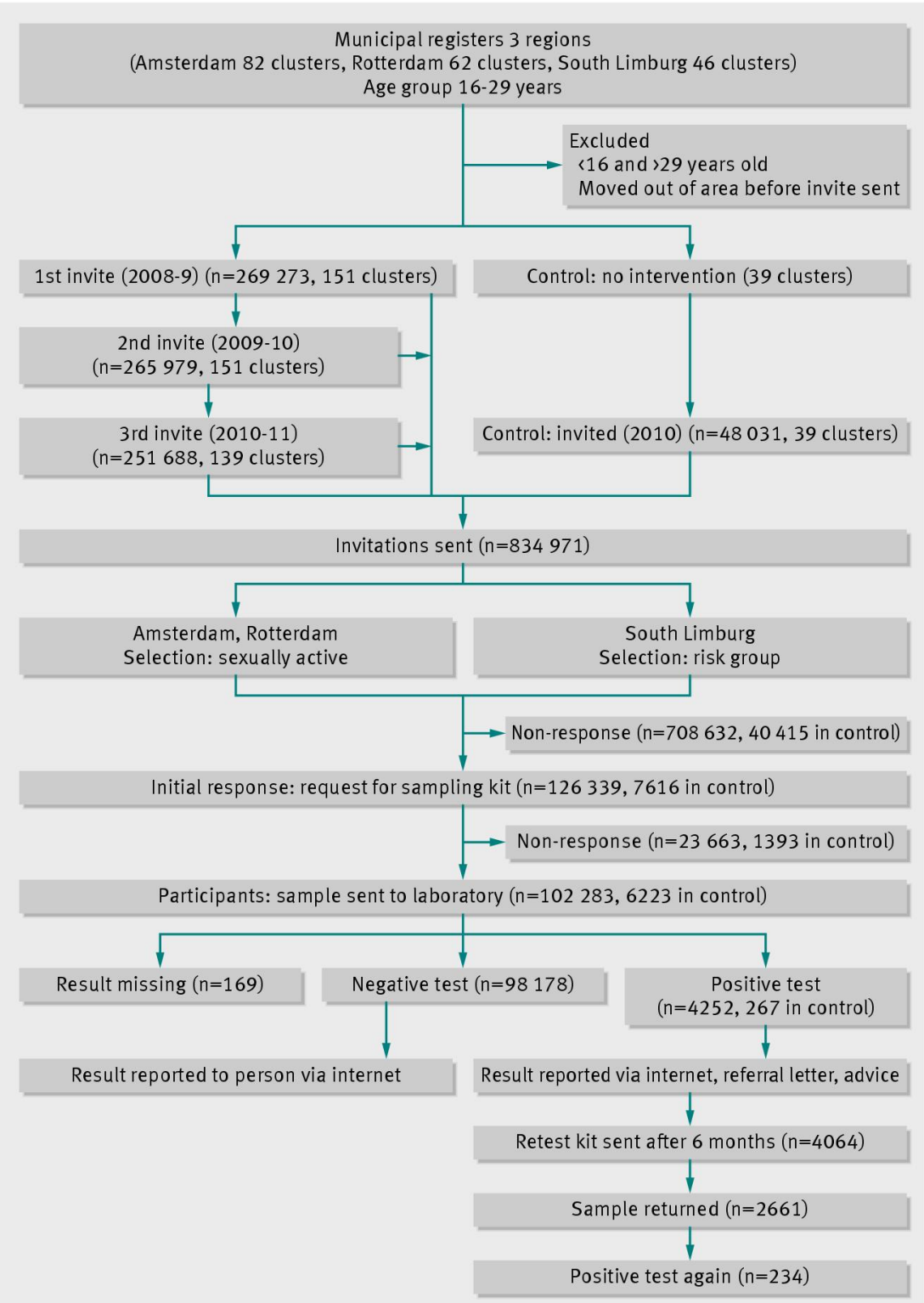

Fig Flow chart of the Chlamydia Screening Implementation programme 